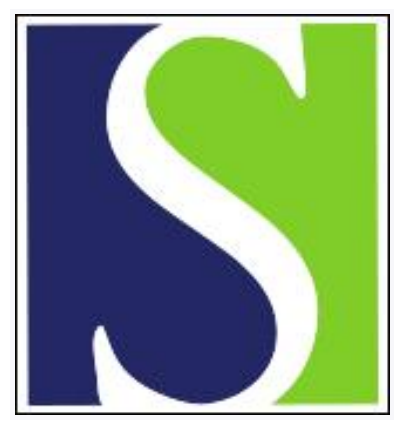

Scand J Work Environ Health 2012;38(3):238-246

https://doi.org/10.5271/sjweh.3263

Published online: 02 Dec 2011, Issue date: May 2012

Tossing and turning - insomnia in relation to occupational stress, rumination, fatigue, and well-being

by Kompier MAJ, Taris TW, van Veldhoven M

Affiliation: Radboud University Nijmegen, Behavioural Science Institute, Po Box 9104, NL-6500 HE Nijmegen, the Netherlands. M.Kompier@psych.ru.nl

Refers to the following texts of the Journal: 2006;32(6):482-492

2006;32(6):493-501 2002;28(1):1-4 2011;37(4):259-261

2006;32(6):502-514

The following articles refer to this text: 2013;39(6):535-549;

2015;41(2):164-174; 2017;43(2):109-116

Key terms: fatigue; insomnia; occupational stress; psychosocial work environment; rumination; sleep quality; well-being; work pleasure

This article in PubMed: www.ncbi.nlm.nih.gov/pubmed/22138930

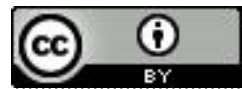




\title{
Tossing and turning - insomnia in relation to occupational stress, rumination, fatigue, and well-being
}

\author{
by Michiel AJ Kompier, PhD, ${ }^{1}$ Toon W Taris, PhD, ${ }^{1,2}$ Marc van Veldhoven, PhD ${ }^{3}$
}

Kompier MAJ, Taris TW, van Veldhoven M. Tossing and turning - insomnia in relation to occupational stress, rumination, fatigue, and well-being. Scand J Work Environ Health. 2012;38(3):238-246. doi:10.5271/sjweh.3263

\begin{abstract}
Objectives This study of a large and heterogeneous sample of 5210 daytime employees was designed to shed more light on the work effort-recovery mechanism by examining the cross-sectional relations between subjective sleep quality and (i) psychosocial work characteristics, (ii) work-related rumination, (iii) fatigue after work, and (iv) affective well-being at work and work pleasure.
\end{abstract}

Methods We used the Dutch Questionnaire on the Experience and Evaluation of Work and created three sleep quality groups (low, low-to-intermediate, and high quality). Group differences were studied through analysis of variance (ANOVA). To examine the relations among the study variables in more detail, we also conducted four sets of stepwise regression analyses. In all the analyses, we corrected for age, level of education, and gender.

Results A series of (M)ANOVA provided strong evidence for a relation between sleep quality and adverse work characteristics and work-related rumination. Furthermore, poor sleepers reported higher levels of fatigue after work, and poor sleep quality was related to both lower affective well-being during work and work pleasure. Regression analyses revealed that sleep quality was the strongest statistical predictor of after-work fatigue and affective well-being at work, and high levels of work rumination constituted the strongest statistical predictor of sleep complaints.

Conclusions As this study showed strong relations between sleep quality, occupational stress, fatigue, perseverative cognitions, and work motivation, it supports effort-recovery theory. Interventions should aim to prevent a disbalance between effort and recovery.

Key terms psychosocial work environment; sleep quality; work pleasure.

One of the challenges of occupational health psychology is to clarify the mechanisms that may explain how combinations of stressful psychosocial work characteristics in the long-term may cause ill-health (1). One such mechanism is the psycho-physiological effort-recovery mechanism $(2,3)$. It holds that, in the case of prolonged or repeated (daily) exposure to stressful work characteristics combined with insufficient recovery and coping possibilities, a cumulative process may start in which psychophysiological reactions that initially were adaptive and reversible are sustained and in the long run may result in subsequent adverse health. Within effort-recovery theory and comparable theoretical approaches, such as allostatic load theory (4-6) and the cognitive activation theory of stress (7), recovery is a process of psycho-physiological unwinding that is the opposite of the activation of the sympathetic-adrenal-medullary system and the hypothalamic-pituitary-adrenal system during effort expenditure, particularly under stressful conditions (3). According to effort-recovery theory, recovery is an important intervening variable in the hypothesized causal chain between the exposure to a stressful psychosocial work environment and the development of acute load reactions and also in the gradual transformation from acute load reactions ("sustained activation") into more chronic and serious load reactions and, eventually, ill-health.

1 Behavioural Science Institute, Radboud University Nijmegen, the Netherlands.

2 Department of Work and Organizational Psychology, Utrecht University, the Netherlands.

3 Department of Human Resource Studies, Tilburg University, the Netherlands

Correspondence to: Michiel Kompier, Radboud University Nijmegen, Behavioural Science Institute, PO Box 9104, NL-6500 HE Nijmegen, the Netherlands. [E-mail: M.Kompier@psych.ru.nl]. 
Sleep is the prototypical recovery activity. It is essential for physiological balance, long-term health and mental functioning $(8,9)$. Sleep is important for the restoration of alertness, mood, and performance capacity. It also regenerates the central nervous system, the metabolic system, the endocrine system, and the immune system. In the long run, reduced or impaired sleep leads to metabolic diseases, depression, burnout, and mortality (9). Insufficient sleep is also a cause of poor work performance and work accidents (8). Poor sleep is mainly a matter of sleep (dis)continuity. Over the years, research concerning sleep quality and insomnia has been hampered by a lack of widely accepted operational research diagnostic criteria for their definition. However, according to a report of an American Academy of Sleep Medicine Work Group (10, p1580), research diagnostic criteria for insomnia disorder include one or more of the following sleep-related complaints: (i) difficulty initiating sleep; (ii) difficulty maintaining sleep; (iii) waking up too early; and (iv) sleep that is chronically non-restorative or poor in quality.

Although common sense holds that occupational stress disturbs sleep, there have been remarkably few studies on the effects of everyday work stress on sleep quality and related fatigue $(8,11-16)$. Therefore, in his review of psychosocial stress and impaired sleep, Åkerstedt (8, p498) concludes: "In summary, stress and sleep seem intimately connected, but there is much need for more systematic research". The study of self-reported quality of sleep offers an interesting possibility for the study of stress and sleep, and more recently several prospective studies were published. Åkerstedt et al (17) found that self-reported disturbed sleep and fatigue predict later long-term sickness absence. Similarly, in a prospective study, Sivertsen et al (18) reported that insomnia was a strong predictor of subsequent permanent work disability. In another prospective study in a large sample of 50-60-year old employees, evidence was found that work-related stressors were associated with the development and maintenance of insomnia (19). Also, Linton (16), in a population free from sleep complaints at baseline found an association between psychosocial work stress at baseline and the development of sleep complaints during a 1-year follow-up. In another longitudinal study among 1163 Dutch employees, De Lange et al (20) found significant effects of job demands and control on sleep quality and fatigue across a 1-year time lag. These authors further showed that a transition from a non-high to a high strain job was associated with a significant increase in sleep-related complaints. This suggests a causal path from psychosocial work factors to sleep problems, thus supporting the effort-recovery mechanism.

The present study was designed to shed more light on the work effort-recovery mechanism, first by investigating the associations between stressful psychosocial work characteristics and subjective sleep quality (question 1). Following Edinger et al's typology (10), we use an extensive assessment of sleep quality. Whereas previous research often concentrated on one or a few psychosocial work characteristics $(13, \mathrm{p} 1720$; 16 , p134), this study utilizes a fine-grained and valid assessment of the full psychosocial work environment. We also differentiate between those work characteristics that, according to an overview of the most important occupational stress and well-being theories (21), can be considered to be major psychosocial work features. We address other limitations of previous work in this field as well. Specifically, whereas most previous studies utilized relatively small and homogeneous samples (13, p1720), we employ a large national and heterogeneous sample. Also, while other studies did not consistently take possible confounding by shift work into account, we selected daytime workers only (13).

One path through which psychosocial work features may impact on sleep may be a cognitive process of work pre-occupation that may prolong physiological activation and thus hamper "unwinding". Polysomnographical studies suggest that situations involving the anticipation of increased demands interfere with sleep (8). Rumination at bedtime and the anticipation of increased demands may be one of the key factors behind sleeping problems (22). Further support for the role of work pre-occupation in the understanding of insomnia comes from an epidemiological study among middle-aged Finnish citizens (23). In this study, disturbed sleep was not only related to a large volume of work and workrelated fatigue but also work-related worries. Other supportive evidence stems from a prospective US study (24), showing that being bothered or upset frequently at work predicted changes towards poorer sleep quality. As findings from laboratory research (eg, 25, 26) also suggest that ruminative and anticipatory thoughts about stressors may impede psycho-physiological recovery, our second research question is to what extent selfreported sleep quality is related to work-related rumination (question 2).

Fatigue after work constitutes another indicator of an imbalance between effort and recovery (2). The concept of fatigue is closely related to sleepiness and the two are often used as synonyms (9). Fatigue is a waking correlate and consequence of insomnia. Fatigue is also the main characteristic of the burnout syndrome. Accordingly, we hypothesize that sleep quality will be related to fatigue after work (question 3).

Finally, occupational health psychology has a certain bias to the negative (ie, to concentrate on the negative consequences of working for worker health and well-being). However, work is not necessarily stressful and may also result in positive outcomes for workers. Therefore we also investigated the potential relationship 
between sleep quality and two (positive, motivational) indicators of occupational well-being, namely, affective well-being at work and work pleasure (question 4).

\section{Methods}

\section{Participants}

Dutch occupational health services collected questionnaire data from 12505 respondents between 1995-1998, using scales and items of the Dutch Questionnaire on the Experience and Evaluation of Work (VBBA) (27). Because of the context in which data were collected (ie, practical research on psychosocial job conditions and job stress), no direct figures on response rates were available. In previous research using this questionnaire, response rates typically ranged between $60-80 \%$ (28). For the present study, we selected participants from the total database for whom information was available regarding gender, age, educational level, sleep quality, and all of the other relevant measurement scales (see section on measures). Thus, participants with missing values on any of the study variables were omitted from the dataset. Furthermore, all participants were required to work for $\geq 24$ hours per week to be eligible for the study; those working night shifts, shift work, or irregular hours were omitted from the sample. This resulted in a study population of 5210 respondents ( $52 \%$ male, $48 \%$ female; mean age 38.9 [standard deviation (SD) 11.2] years; $45 \%$ held a college or university degree).

\section{Measures}

All concepts were measured using scales of the VBBA (27), which is widely used in Dutch occupational health services and applied research on psychosocial work characteristics and job stress in the Netherlands. Validity evidence with respect to the VBBA scales has been provided elsewhere (eg, 28, 29). As shown in table 1, all scales possess acceptable-to-good reliability (Cronbach's alphas).

Criterion variables. Sleep quality was assessed with 12 items obtained from Meijman et al (30). In line with Edinger et al's (10) research diagnostic criteria for insomnia disorder, we included items covering difficulties with initiating sleep (eg, "Usually, I fall asleep very easily" - reversed), difficulties maintaining sleep (such as "I often wake up several times during the night"), and sleep quality in general (including "I find that I sleep very badly in general") ( $0=$ "no", $1=$ "yes"). In order to prevent content overlap, two fatigue-related items (eg, "After I get up, I often have the feeling that I am tired") that are present in the original scale (30) were not included in our sleep quality score. An exploratory factor analysis on the 12 items revealed a single factor that accounted for $37 \%$ of the variance in the items.

Three items concerned work-related rumination, namely "I can easily detach myself from my work" (reversed), "During my free time, I often worry about my work", and "When I leave my work, I continue to worry about work problems" (0="no", 1="yes").

Fatigue after work was measured with 11 dichotomous items, eg, "By the end of the working day, I feel really worn out" and "When I get home from work, I need to be left in peace for a while" (1="no", $2=$ =yes"). A higher score reflects more fatigue.

Affective well-being during work was measured with six items that were based on Warr (31) (eg, optimistic, relaxed). All items had 4 response categories: $0=$ "absolutely not", $1=$ "hardly ever", $2=$ "somewhat", $3=$ "completely". These were recoded into two categories: "absolutely not" and "hardly ever" $=0$, "somewhat" and "completely" $=1$. A higher score reflects more affective well-being.

Work pleasure was measured with 9 items [eg, "I enjoy my work" and "I do my work because I have to, and that says it all" (reversed); 0="no", 1="yes"]. A higher score reflects more work pleasure.

Work characteristics. All items of all work characteristics scales had four response categories: $4=$ always, $3=$ often, $2=$ sometimes, and 1=never. Pace and amount of work was measured with 11 items, including "Do you have to work very fast?" Emotional load was measured using 7 items, such as "Does your work demand a lot from you emotionally?" Physical effort was addressed with 7 items, including "Does your work require physical strength?" Work variety was measured with 6 items, including "Is your work varied?" Work control was measured with 11 items, including "Do you have freedom in carrying out your work activities?" Colleague support was measured with 9 items, such as "Can you count on your colleagues when you encounter difficulties in your work?" These 9 items were slightly adapted to address supervisor support, for example, "Can you count on your superior when you encounter difficulties in your work?" Average scores were calculated for each work characteristic scale, with higher scores reflecting more of the phenomenon.

Background variables. We recorded age (in years), sex, and level of education (with six levels: 1=primary education, not completed $(0.3 \%) ; 2=$ primary education, completed (4\%); $3=$ lower vocational training completed, or higher secondary education, not completed (18.8\%); $4=$ higher secondary education (nearly) completed (31.2\%); $5=$ higher education/college degree $(31.4 \%)$; and $6=$ higher education/university degree $(14.3 \%)$. 
Table 1. Means, standard deviations (SD) and correlations for the study variables $N=5208$. Correlations of $\geq 0.04$ are significant at $P<0.01$.

\begin{tabular}{|c|c|c|c|c|c|c|c|c|c|c|c|c|c|c|}
\hline Variables & Mean & SD & 1 & 2 & 3 & 4 & 5 & 6 & 7 & 8 & 9 & 10 & 11 & 12 \\
\hline $\begin{array}{l}1 \text { Pace/amount of } \\
\text { work }\end{array}$ & 2.40 & 0.45 & $0.88^{a}$ & & & & & & & & & & & \\
\hline 2 Emotional load & 1.89 & 0.43 & 0.44 & $0.78^{a}$ & & & & & & & & & & \\
\hline 3 Physical effort & 1.46 & 0.54 & 0.04 & -0.02 & $0.88^{a}$ & & & & & & & & & \\
\hline 4 Work variety & 2.95 & 0.55 & 0.15 & 0.29 & -0.25 & $0.82^{\mathrm{a}}$ & & & & & & & & \\
\hline 5 Work control & 2.83 & 0.52 & -0.12 & 0.04 & -0.28 & 0.38 & $0.89 \mathrm{a}$ & & & & & & & \\
\hline 6 Colleague support & 3.29 & 0.42 & -0.21 & -0.22 & -0.10 & 0.13 & 0.21 & $0.82^{a}$ & & & & & & \\
\hline 7 Supervisor support & 3.28 & 0.51 & -0.22 & -0.22 & -0.12 & 0.15 & 0.25 & 0.51 & $0.88^{a}$ & & & & & \\
\hline 8 Rumination & 1.29 & 0.44 & 0.36 & 0.28 & -0.03 & 0.09 & -0.05 & -0.21 & -0.19 & $0.78^{a}$ & & & & \\
\hline 9 Fatigue after work & 1.29 & 0.26 & 0.45 & 0.31 & 0.11 & 0.00 & -0.15 & -0.24 & -0.26 & 0.47 & $0.88^{a}$ & & & \\
\hline $\begin{array}{l}10 \text { Affective well-being } \\
\text { during work }\end{array}$ & 1.66 & 0.48 & -0.25 & -0.12 & -0.01 & 0.08 & 0.11 & 0.19 & 0.24 & -0.31 & -0.37 & $0.90^{a}$ & & \\
\hline 11 Work pleasure & 1.93 & 0.16 & -0.16 & -0.12 & -0.08 & 0.20 & 0.18 & 0.22 & 0.27 & -0.23 & -0.31 & 0.35 & $0.80^{a}$ & \\
\hline 12 Sleep quality & 1.84 & 0.22 & -0.21 & -0.15 & -0.12 & 0.08 & 0.13 & 0.17 & 0.19 & -0.38 & -0.46 & 0.30 & 0.27 & $0.77^{\mathrm{a}}$ \\
\hline
\end{tabular}

a Reliabilities Cronbach's alpha.

\section{Statistical analysis}

Research questions 1-4 referred to the associations between sleep quality and (i) psychosocial work characteristics (Q1); (ii) work-related rumination (Q2); and (iii) fatigue after work (Q3) and (iv) affective well-being at work and work pleasure (Q4). In order to address these questions, we created three sleep quality groups of about equal size: one group without sleep complaints, one group with low-to-intermediate level of sleep complaints (1-2 complaints), and one group with a high level of sleep complaints $(\geq 3)$. We tested between-group differences among the four clusters of study variables using a 3 (sleep quality: low versus intermediate versus high quality) $\times 2$ (gender: male versus female) $\times 3$ (level of education: low versus intermediate versus high) $\times 3$ (age: young versus intermediate versus old) multivariate analysis of variance (MANOVA). As we did not have any expectations concerning the possible interactions of sleep quality with the control variables age, gender, and level of education, we only tested the two-way interactions between sleep quality and the three control variables. Due to the large sample size, we employed an alpha level of 0.01 rather than 0.05 to ensure that statistically significant differences between the means of groups were also practically relevant. Significant multivariate findings for sleep quality were followed by univariate ANOVA with post-hoc comparisons to examine which sleep quality groups differed from the other sleep quality groups. As the assumption that the variance of all criterion variables was homogeneous across all sleep quality groups could not be maintained, we employed Tamhane's range test for these comparisons. Moreover, we computed Cohen's D for all comparisons (ie, high versus intermediate sleep quality; high versus low sleep quality; and intermediate versus low sleep quality groups) as an indication of effect size. For brevity, rather than presenting all of these, we present only the largest $\mathrm{D}$-value for each comparison (Max $D$ ). Following Cohen (32), we distinguished among small $(<0.5)$, medium $(0.5-0.8)$ and large $(>0.8)$ effect sizes.

To examine the relations among the study variables in more detail, we conducted four sets of stepwise regression analyses, one for each of the four criterion variables (fatigue after work, affective well-being during work, work pleasure, and sleep quality, respectively). In the first block of all analyses (models M0) we entered age, sex, and level of education. These variables serve as control variables and are not of substantive interest; they were entered first in order not to overestimate the effects of the other predictors. In the second block (M1), we entered our focal variable sleep quality (for fatigue after work, affective well-being during work, and work pleasure). For sleep quality, the second block included the seven psychosocial work characteristics. These work characteristics were also entered in the three other regression analyses (models M2). In this way, it is possible to examine whether the associations between sleep quality, on the one hand, and fatigue after work, affective wellbeing during work and work pleasure, on the other hand, hold up after controlling for work characteristics.

\section{Results}

Table 1 presents descriptive information for all study variables. Table 2 presents descriptive information for the three sleep quality groups (high versus intermediate versus low quality). The first group reported no sleeping complaints (high sleep quality, $\mathrm{N}=1925$, $36.9 \%$ ); the second group reported low-to-intermediate 
Table 2. Descriptive information [crude and adjusted means and crude standard deviations (SD) for the study variables, and distributions of age, gender and level of education] as a function of level of sleep quality (adjusted means adjusted for gender, age and level of education). All univariate $F$ for sleep quality have $(2,5339)$ degrees of freedom and were significant at $P<0.001$. All multivariate $F$ for the main effects of gender, age, and level of education were significant $(P<0.001)$; none of the two-way interactions between sleep quality, on the one hand, and gender, age, and level of education, on the other hand, were significant at $P<0.01$. [Max $D=$ largest $D$-value for each comparison]

\begin{tabular}{|c|c|c|c|c|c|c|c|c|c|c|c|c|c|c|}
\hline \multirow[t]{3}{*}{ Variables } & \multicolumn{12}{|c|}{ Sleep quality a } & \multirow[t]{3}{*}{$\mathrm{F}$} & \multirow[t]{3}{*}{$\operatorname{Max} D^{b}$} \\
\hline & \multicolumn{4}{|c|}{ High $(\mathrm{N}=1925)$} & \multicolumn{4}{|c|}{ Intermediate $(\mathrm{N}=1892)$} & \multicolumn{4}{|c|}{ Low $(N=1391)$} & & \\
\hline & Mean & $\begin{array}{c}\text { Adjusted } \\
\text { mean }\end{array}$ & $\mathrm{SD}$ & $\%$ & Mean & $\begin{array}{c}\text { Adjusted } \\
\text { mean }\end{array}$ & $\mathrm{SD}$ & $\%$ & Mean & $\begin{array}{c}\text { Adjusted } \\
\text { mean }\end{array}$ & $\mathrm{SD}$ & $\%$ & & \\
\hline Pace/amount of work ${ }^{c}$ & 2.27 & 2.29 & 0.42 & & 2.42 & 2.42 & 0.45 & & 2.54 & 2.53 & 0.48 & & 123.4 & 0.55 \\
\hline Emotional load c & 1.80 & 1.80 & 0.41 & & 1.91 & 1.91 & 0.43 & & 1.99 & 1.98 & 0.46 & & 78.9 & 0.44 \\
\hline Physical effort c & 1.41 & 1.42 & 0.51 & & 1.46 & 1.48 & 0.55 & & 1.54 & 1.55 & 0.57 & & 24.7 & 0.24 \\
\hline Work variety ${ }^{c}$ & 2.98 & 2.96 & 0.55 & & 2.97 & 2.96 & 0.54 & & 2.89 & 2.87 & 0.57 & & 13.9 & 0.16 \\
\hline Work control c & 2.89 & 2.88 & 0.52 & & 2.83 & 2.83 & 0.51 & & 2.74 & 2.74 & 0.54 & & 29.4 & 0.28 \\
\hline Colleague support ${ }^{c}$ & 3.36 & 3.36 & 0.41 & & 3.28 & 3.29 & 0.41 & & 3.19 & 3.20 & 0.43 & & 66.0 & 0.40 \\
\hline Supervisor support c & 3.39 & 3.39 & 0.47 & & 3.28 & 3.28 & 0.51 & & 3.14 & 3.14 & 0.55 & & 93.9 & 0.49 \\
\hline Rumination ${ }^{\mathrm{c}}$ & 1.15 & 1.15 & 0.27 & & 1.28 & 1.28 & 0.35 & & 1.51 & 1.50 & 0.41 & & 436.8 & 1.01 \\
\hline Fatigue after work ${ }^{c}$ & 1.14 & 1.14 & 0.21 & & 1.29 & 1.29 & 0.28 & & 1.49 & 1.48 & 0.32 & & 646.0 & 1.29 \\
\hline $\begin{array}{l}\text { Affective well-being } \\
\text { during work }{ }^{c}\end{array}$ & 1.80 & 1.78 & 0.29 & & 1.69 & 1.69 & 0.40 & & 1.45 & 1.45 & 0.55 & & 214.0 & 0.70 \\
\hline Work pleasure ${ }^{c}$ & 1.97 & 1.97 & 0.10 & & 1.93 & 1.93 & 0.16 & & 1.86 & 1.86 & 0.25 & & 143.4 & 0.37 \\
\hline Male & & & & 53.3 & & & & 53.5 & & & & 49.9 & & \\
\hline Female & & & & 46.7 & & & & 46.5 & & & & 50.1 & & \\
\hline Low education ${ }^{d}$ & & & & 38.2 & & & & 39.1 & & & & 34.9 & & \\
\hline Medium education ${ }^{\mathrm{e}}$ & & & & 31.7 & & & & 30.6 & & & & 28.0 & & \\
\hline High education ${ }^{f}$ & & & & 30.1 & & & & 30.3 & & & & 37.1 & & \\
\hline Young ( $\leq 33$ years) & & & & 27.1 & & & & 25.6 & & & & 29.3 & & \\
\hline Intermediate (34-43 years) & & & & 29.0 & & & & 29.7 & & & & 30.1 & & \\
\hline Old ( $\geq 44$ years) & & & & 43.9 & & & & 44.6 & & & & 40.6 & & \\
\hline
\end{tabular}

a Multivariate $F(22,10624)=70.2, P<0.001$.

${ }^{b}$ For all comparisons the highest $D$-value was obtained for the high versus the low-sleep quality groups.

${ }^{c}$ All means differ significantly from each other, $P<0.01$.

a Primary education (completed or uncompleted), completed lower vocational training, or uncompleted higher secondary training.

e Higher secondary education (nearly) completed.

${ }^{f}$ College or university degree.

levels of sleeping complaints (intermediate sleep quality, $\mathrm{N}=1892,36.3 \%$ ); and the third group reported high levels of sleep complaints (low sleep quality, $\mathrm{N}=1391$, 26.7\%). Table 2 shows that female and older participants were slightly overrepresented in the low sleep quality group as compared to males and younger participants, and highly educated participants were overrepresented in the high and intermediate sleep quality groups. The average number of sleeping complaints reported by participants in these three groups was 0.0 (SD 0.0), 1.5 (SD 0.7 ), and 5.5 (SD 2.6), respectively, $\mathrm{F}(2,6127)=7,566.3$, $\mathrm{P}<0.001$, showing that they differed strongly in terms of their reported sleep quality.

Table 2 also presents the crude and adjusted means and SD for all study variables as a function of sleep quality. The overall MANOVA F-tests for the main effects were significant: gender, $\mathrm{F}(11,5311)=23.0$; level of education, $\mathrm{F}(22,10624)=63.7$; age, $\mathrm{F}(22,10624)=18.8$, and sleep quality, $F(22,10624)=70.2$; however, none of the three two-way interactions between gender, level of education and age, on the one hand, and sleep quality, on the other hand, was significant (all $\mathrm{P}>0.01$ ). Thus, although gender, level of education, and age accounted for a significant proportion of the variance in the study variables, the associations between these variables and our focal variable sleep quality did not vary as a function of these control variables. Consequently, in our further analyses, we control for age, gender, and level of education, but do not discuss their effects in detail.

Subsequent univariate ANOVA for sleep quality (controlling for age, gender, and level of education) revealed that the three sleep quality groups differed significantly on all study variables, $\mathrm{F}(2,5339)>134.9$, $\mathrm{P}<0.001$. Regarding the cluster of psychosocial work characteristics (Q1), table 2 shows that the high sleep quality group consistently obtained the most favorable scores on work characteristics, whereas the low sleep quality group always obtained the least favorable scores. Post-hoc analyses revealed that the differences in the means of these groups were always statistically significant. Thus, adverse psychosocial work characteristics are indeed associated with low sleep quality. Moreover, the D-values for the work characteristics varied from $0.16-0.55$ (median $\mathrm{D}=0.40$ ), indicating weak-to-medium-sized effects.

Table 2 shows that sleep quality is negatively 
associated with work-related rumination (Q2). Again, workers reporting low sleep quality reported the highest levels of rumination; the reverse applied to workers reporting high sleep quality. Note that the difference among the means of these groups was large, as signified by a strong Cohen's D of 1.01. Q3 referred to levels of fatigue after work. As expected, the least favorable scores were obtained for those reporting low sleep quality. Again, at a value of 1.29 , Cohen's D was strong. Finally, the lowest levels of affective well-being during work and work pleasure (Q4) were obtained for workers reporting low sleep quality. The D-values obtained here were 0.70 (medium effect) and 0.37 (small effect), respectively.

\section{Regression analysis}

The findings presented in tables 1 and 2 show that low sleep quality is systematically associated with adverse scores on a range of psychosocial work characteristics, rumination, and indicators of worker well-being, which is consistent with the reasoning that (i) sleep quality is a major determinant of well-being and (ii) adverse work characteristics may impede sleeping well. To examine this reasoning and the interrelations among the study concepts in more detail, we conducted four regression analyses (one for each of the three well-being indicators and one for sleep quality), the results of which are reported in table 3 . Note that these analyses always included the main effects of age, gender, and level of education, since these variables accounted for a statistically significant proportion of the variance in the well-being indicators and because these concepts are related to sleep quality (cf. table 2). These analyses also revealed that neither gender, age, nor level of education moderated the associations between sleep quality and the criterion variables; therefore, the corresponding interaction effects were not included in the regression analyses.

Well-being and sleep quality. The first three sets of findings presented in table 3 refer to the statistical prediction of fatigue after work, affective well-being during work, and work pleasure, respectively. Age, sex, and level of education were controlled for in each of these analyses (not reported for brevity; results are available upon request). Subsequently sleep quality was entered as a statistical predictor of the respective well-being indicator (M1 in table 3). As table 3 shows, in all three analyses, low sleep quality was associated with adverse well-being (ie, high levels of fatigue after work, low levels of affective well-being during work, and low work pleasure). The magnitude of the respective betas varied from 0.26 (for work pleasure) to 0.45 (for fatigue after work). On average, sleep quality accounted for an additional $12 \%$ of the variance in the indicators of well- being. This figure decreased substantially after inclusion of the work characteristics and work-related rumination (M2). However, the association between sleep quality and well-being remained significant: on average sleep quality still accounted for $4.6 \%$ of the variance in the three criterion variables. Inspection of the betas in table 3 shows that sleep quality consistently ranked among the most important correlates of well-being. It was the strongest statistical predictor of fatigue after work and affective well-being during work and the second strongest correlate of work pleasure (after-work variety).

As regards the other statistical predictors of fatigue after work, affective well-being during work, and work pleasure, the three work characteristics that were most consistently related were pace/amount of work and support from supervisor and colleagues, which were associated with all three variables. Emotional load and work control and variety were related to two of these three measures; physical effort was only associated with fatigue after work. Table 3 shows that adverse wellbeing was associated with higher (i) pace/amount of work, emotional load, and physical effort and (ii) lower work variety and control and decreased support from colleagues and the supervisor. That is, these effects were always in the expected direction. As regards rumination, higher levels of rumination were associated with adverse scores on all three indicators of well-being. Again, these effects were in the expected direction.

Correlates of sleep quality. Given the apparent importance of sleep quality as a "predictor" of well-being, it is interesting to examine in more detail which workrelated concepts are associated with sleep quality. The fourth regression analysis presented in table 3 shows that high levels of work-related rumination was by far the strongest statistical predictor of low sleep quality (beta $=-0.34, \mathrm{P}<0.001$ ), accounting for $11.6 \%$ of the variance in sleep quality. Although 5 out of 7 work characteristics included in table 3 were significantly associated with sleep quality, the magnitude of these associations was relatively small (range 0.04-0.09, median 0.08). Thus, although the direction of these associations was always in the expected direction, workrelated rumination was the most important correlate of sleep quality.

\section{Discussion}

"Life is about effort and restitution of effort" (9, p205). Sleep is essential in the process of recovery from effort. One major obstacle to sleep is stress because stress produces significant psycho-physiological activation that is at odds with the requirement of psycho-physiological 
Table 3. Results of five sets of hierarchical regression analyses (standardized betas, $\mathrm{N}=5205)$. All models included age, sex, and level of education as control variables (for brevity, these estimates are not reported here). M1 included the control variables as well as sleep quality (for fatigue after work, affective well-being during work, and pleasure in work); for sleep quality, M1 included only the work characteristics. M2 included the variables included in M1 as well as the work characteristics and rumination. All $\mathrm{R}^{2}$ and $\Delta \mathrm{R}^{2}$ significant at $\mathrm{P}<0.001$.

\begin{tabular}{|c|c|c|c|c|c|c|c|}
\hline & \multicolumn{2}{|c|}{ Fatigue after work } & \multicolumn{2}{|c|}{ Affective well-being during work } & \multicolumn{2}{|c|}{ Work pleasure } & \multirow{2}{*}{$\frac{\text { Sleep quality }}{\text { M1 }}$} \\
\hline & M1 & M2 & M1 & M2 & M1 & M2 & \\
\hline Sleep quality & $-0.45^{a}$ & $-0.28{ }^{a}$ & $0.31^{\text {a }}$ & $0.19^{a}$ & $0.26^{a}$ & $0.15^{\mathrm{a}}$ & $\cdot$ \\
\hline Pace/amount of work & & $0.24^{a}$ & & $-0.15^{a}$ & & $-0.04 b$ & $-0.04 b$ \\
\hline Emotional load & & $0.10^{a}$ & & 0.03 & & $-0.06^{a}$ & $-0.05^{a}$ \\
\hline Physical effort & & $0.08^{a}$ & & 0.01 & & -0.001 & -0.08 a \\
\hline Work variety & & -0.02 & & 0.09 a & & $0.20 \mathrm{a}$ & 0.09 a \\
\hline Work control & & $-0.04 b$ & & -0.01 & & $0.05^{b}$ & 0.02 \\
\hline Colleague support & & $-0.04^{b}$ & & $0.05^{b}$ & & $0.06^{a}$ & 0.01 \\
\hline Supervisor support & & $-0.05^{a}$ & & $0.10^{a}$ & & $0.11^{\mathrm{a}}$ & $0.07^{\text {a }}$ \\
\hline Rumination & & $0.23^{a}$ & & -0.17 a & & $-0.11^{a}$ & $-0.34^{a}$ \\
\hline $\mathrm{R}^{2}$ & 0.22 & 0.42 & 0.13 & 0.21 & 0.07 & 0.17 & 0.18 \\
\hline$\Delta \mathrm{R}^{2}$ & 0.20 & 0.20 & 0.09 & 0.09 & 0.07 & 0.10 & 0.17 \\
\hline
\end{tabular}

deactivation during sleep. Whereas common sense holds that occupational stress disturbs sleep, there is a need for systematic studies in this area $(8,13,15,16,19,24)$. Against this background, the present study investigated the relations between sleep quality and psychosocial work characteristics (Q1), work-related rumination (Q2), fatigue after work (Q3), and affective well-being at work and work pleasure (Q4).

We found clear evidence of a relation between adverse psychosocial work characteristics and poor sleep quality (Q1). We also found that sleep quality was negatively related to work-related rumination $(\mathrm{Q} 2)$, and poor sleepers reported higher fatigue levels after work (Q3). Poor sleep quality was also related to lower affective well-being at work and work pleasure (Q4). In a series of regression analyses, we investigated the relations between the main study variables in more detail and found that sleep quality was the strongest statistical predictor of after-work fatigue and affective well-being during work and the second strongest statistical predictor of work pleasure. We also found that high levels of work-rumination constituted the strongest statistical predictor of sleep complaints. Although sleep quality per se was related to age, gender, and educational level, the associations that were demonstrated in this study (Q4) were not dependent on differences in age, gender, and level of education.

All in all, the common sense notion of a firm association between occupational stress and sleep receives strong support in this study (Q1 results). As this association has also been demonstrated in other recent studies that link psychosocial stressors at work, measured at baseline, to sleep problems at follow-up (eg, 16, 19, 20 ), we consider this relation to be a robust finding. Our second research question (work-related rumination) has received less research attention. As expected, this study points to a major role of work-related cognitive processes in this work stress-sleep relation: work-related rumination was the strongest correlate of sleep complaints. As such this study corroborates the prospective study of Burgard \& Ailshire (24), which showed that frequently being bothered or upset at work is associated with poorer sleep quality and that this association could not be explained by stressful experiences at home. The clear associations between sleep quality and fatigue after work (Q3) may imply that, in a cumulative process of day-to-day effort at work in combination with insufficient recovery, poor sleep and fatigue are two sides of the same coin. Both phenomena may be manifestations of a poor balance between effort and recovery and may well influence each other. Most interestingly in this study, poor sleep is also related to decreased work pleasure (Q4), which is in accordance with the notion of fatigue as involving both the inability and the unwillingness to continue or perform an activity $(2,33)$.

Though still somewhat speculative, this study's results picture a vicious circle between stressors at work, sleep quality, (emotional and cognitive) work preoccupation, and daytime fatigue. It may well be that these phenomena influence each other in a circular process, in which factors not only influence other factors but are also influenced by other factors (reciprocal relations) (see also 34). Stressors at work play a key role in the development and maintenance of this process. They may cause sustained activation during work but also after work, and these high levels of arousal may hinder sleep. Work stressors may also become "a fundamental source for disturbing thoughts that become intrusive when a person attempts to sleep" (16, p133). Work pre-occupation (eg, worries about conflicts at work or excessive 
job demands) may create arousal when trying to wind down and even turn into worries about not being able to fall asleep, etc. Daytime consequences of poor sleeping may well be fatigue, but also poor work behavior and performance. Poor work performance, in turn, may also "create" work stressors, such as reduced support from colleagues or supervisors or work insecurity.

We believe that the present study contributes to the literature in several ways. It is based on a large national and heterogeneous sample, and we selected day time workers only to prevent possible confounding by shift work. We also used an extensive and valid assessment of sleep quality and utilized a fine-grained and valid assessment of the psychosocial work environment. In addition, we measured work-related rumination, fatigue, and positive affect. These assets also come with a clear limitation. Our study design is cross-sectional and this hampers the interpretation of our results in causal terms. In line with our speculative account of the vicious circle of work stress and sleep, it seems likely that at least some of the associations reported in this study mirror a two-way process (ie, reflect both normal and reverse causation). For example, the association between poor sleep and work-related rumination may imply that rumination hinders sleep but also that poor sleep starts a process of worrying and perseverative cognitions. Similarly, reduced social support may cause worry and poor sleep, whereas poor sleepers may be less alert and underperform and therefore receive less support than others. Longitudinal designs with more repeated measures on all important variables (eg, work stressors, insomnia, work rumination) may shed more light on different types of causality and on the issue of whether one type of causality is dominant over the other. Also experimental studies may provide more clarity on the role of cognitive and affective processes in the recovery of stress and the development of sleep complaints.

Another limitation of our study is that non-work sources, for example worries over family members, have not been investigated.

Several practical recommendations follow from this work. First, a well-designed psychosocial work environment [ie, a work environment that demands effort and provides sufficient opportunities for recovery both within the working day and between (series of) working days] is vitally important for the prevention of sleep complaints. Providing employees with work time control [ie, an employee's possibilities to control the duration, position, and distribution of his or her work time (35)], may well be a crucial factor in the creation of active jobs: jobs that are both challenging and demanding and provide job incumbents with enough autonomy to effectively cope with regulation problems. On an individual level, recovery after work can be stimulated by seeking activities that are enjoyable and provide distraction, such as sports and exercise (36).
In conclusion, this study found clear evidence for a relation between occupational stress and poor sleep quality, between work-related rumination and poor sleep, and between fatigue after work and poor sleep quality. Poor sleep was also related to (lower) work pleasure. Interventions are needed to prevent an imbalance between work effort and recovery.

\section{References}

1. Kompier M. The psychosocial work environment and health - what do we know and where should we go? Scand J Work Environ Health. 2002;28:1-4.

2. Meijman TF, Mulder G. Psychological aspects of workload. In: Drenth PJ, Thierry HK, De Wolff CJ, editors. Handbook of Work and Organizational Psychology, Vol. 2. 2nd ed. East Sussex: Psychology Press; 1998. p5-33.

3. Geurts SAE, Sonnentag S. Recovery as an explanatory mechanism in the relation between acute stress reactions and chronic health impairment. Scand J Work Environ Health. 2006;32:482-92.

4. Clow A. The physiology of stress. In: Jones F, Bright J, editors. Stress, Myth, Theory, and Research. Harlow, UK: Prentice Hall; 2001. p47-61.

5. McEwen BS. Stress, adaptation, and disease: allostasis and allostatic load. Ann NY Acad Sci. 1998;840:33-44. http:// dx.doi.org/10.1111/j.1749-6632.1998.tb09546.x.

6. Sterling P, Eyer J. Allostasis: a new paradigm to explain arousal pathology. In: Fisher S, Reason J, editors. Handbook on life stress, cognition, and health. Chichester, UK: Wiley; 1990. p629-49.

7. Ursin H, Eriksen HR. The cognitive activation theory of stress. Psychoneuroendocrinology. 2004;29:567-92. http://dx.doi. org/10.1016/S0306-4530(03)00091-X.

8. Åkerstedt T. Psychosocial stress and impaired sleep. Scand J Work Environ Health. 2006;32:493-501.

9. Åkerstedt T, Nilsson PM, Kecklund G. Sleep and recovery. In: Sonnentag, S, Perrewe, PL, Ganster D, editors. Current Perspectives on Job-Stress Recovery. Research on occupational stress and well-being. Emerald Group Publishing Limited; 2009. volume 7. p205-47.

10. Edinger JD, Bonnet MH, Bootzin RB, Doghramji K, Dorsey $\mathrm{CM}$, Espie CA, et al Derivation of Research Diagnostic Criteria for Insomnia: Report of an American Academy of Sleep Medicine Work Group. Sleep. 2004;27:1567-96.

11. Åkerstedt T, Fredlund P, Gillberg M, Jansson B. Work load and work hours in relation to disturbed sleep and fatigue in a large representative sample. J Psychom Res. 2002;53:585-8. http:// dx.doi.org/10.1016/S0022-3999(02)00447-6.

12. Kalimo R, Tenkanen L, Härmä M, Poppius E, Heinsalmi P. Job stress and sleep disorders: findings from the Helsinki Heart Study. Stress Med. 2000;16:65-75. http://dx.doi. org/10.1002/(SICI) 1099-1700(200003)16:2<65::AIDSMI834>3.0.CO;2-8. 
13. Nakata A, Haratani T, Takahashi, S, Kawakami N, Arito H, Kobayashi F, et al Job stress, social support, and prevalence of insomnia in a population of Japanese daytime workers. Soc Sci Med. 2004;59:1719-30. http://dx.doi.org/10.1016/j. socscimed.2004.02.002.

14. Åkerstedt T, Kecklund G, Gillberg M. Sleep and sleepiness in relation to stress and displaced work hours. Physiol Behav. 2007a;92:250-5. http://dx.doi.org/10.1016/j. physbeh.2007.05.044.

15. Lallulka T, Rahkonen O, Lahelma E, Arber S. Sleep complaints in middle-aged women and men: the contribution of working conditions and work-family conflicts. J Sleep Res. 2010;19:466-77. http://dx.doi.org/10.1111/j.13652869.2010.00821.x.

16. Linton SJ. Does work stress predict insomnia? A prospective study. Brit J Health Psychol. 2004;9:127-36. http://dx.doi. org/10.1348/135910704773891005.

17. Åkerstedt T, Kecklund G, Alfredsson L, Selen J. Predicting long-term sickness absence from sleep and fatigue. J Sleep Res. 2007b;16:341-5. http://dx.doi.org/10.1111/j.13652869.2007.00609.x.

18. Sivertsen B, Overland S, Neckelman et al The long-term effect of insomnia on work disability. Am J Epidemiol. 2006;163:1018-24. http://dx.doi.org/10.1093/aje/kwj145.

19. Jansson-Frojmark, M, Lundqvist, D, Lundqvist, N, Linton SJ. Psychosocial work stressors and insomnia: a prospective study on 50-60 year-old adults in the working population. Int J Behav Med. 2007;14:222-8. http://dx.doi.org/10.1007/ BF03002996.

20. De Lange AH, Kompier MAJ, Taris TW, Geurts S, Beckers DG, Houtman IL, et al A hard day's night: a longitudinal study on the relationships among job demands and job control, sleep quality and fatigue. J Sleep Res. 2009;18:374-83. http:// dx.doi.org/10.1111/j.1365-2869.2009.00735.x.

21. Kompier M. Job design and well-being. In: Schabracq M, Winnubst JAM, Cooper CL, editors. The Handbook of work and health psychology. 2nd edition. Chichester: Wiley; 2003. p429-53.

22. Harvey AG, Tang NK, Browning L. Cognitive approaches to insomnia. Clin Psychol Rev. 2005;25:593-611. http://dx.doi. org/10.1016/j.cpr.2005.04.005.

23. Urponen H, Vuori I, Hasan J, Partinen M. Self-evaluations of factors promoting and disturbing sleep: An epidemiological survey in Finland. Soc Sci Med. 1998;26:443-50. http:// dx.doi.org/10.1016/0277-9536(88)90313-9.

24. Burgard, SA, Ailshire, JA. Putting work to bed: stressful experiences on the job and sleep quality. J Health Soc Behav. 2009;50:476-92. http://dx.doi. org/10.1177/002214650905000407.
25. Brosschot JF, Van Dijk E, Thayer JF. Daily worry is related to low heart rate variability during waking and the subsequent nocturnal sleep period. Int J Psychophysiol. 2007;63:39-47. http://dx.doi.org/10.1016/j.ijpsycho.2006.07.016.

26. Radstaak, M., Geurts, SAE, Brosschot, JF, Cillessen, AHN, Kompier, MAJ. The role of affect and rumination in cardiovascular recovery from stress. Int $J$ Psychophysiol. 2011;81,3:237-44. http://dx.doi.org/10.1016/j. ijpsycho.2011.06.017.

27. Van Veldhoven M, Meijman TF. Het meten van psychosociale arbeidsbelasting met een vragenlijst: de vragenlijst beleving en beoordeling van de arbeid (VBBA) [The measurement of psychosocial workload by means of a questionnaire: the Dutch questionnaire on the experience and evaluation of work]. Amsterdam: NIA, 1994

28. Van Veldhoven M, Taris TW, De Jonge J, Broersen S. The relationship between work characteristics and employee health and well-being: how much complexity do we really need? Int J Stress Manag. 2005;12:3-28. http://dx.doi.org/10.1037/10725245.12.1.3.

29. Van Veldhoven M, Broersen S. Measurement quality and validity of the 'need for recovery scale'. Occup Environ Med. 2003;60 (Suppl 1): i3-i9. http://dx.doi.org/10.1136/oem.60. suppl_1.i3.

30. Meijman TF, Thunnissen MJ, De Vries-Griever AGH. The after-effects of a prolonged period of day-sleep on subjective sleep quality. Work Stress. 1990;4:65-70. http://dx.doi. org/10.1080/02678379008256965.

31. Warr PB. The measurement of well-being and other aspects of mental health. J Occup Psychol. 1990;63:193-219. http:// dx.doi.org/10.1111/j.2044-8325.1990.tb00521.x.

32. Cohen J. Statistical power analysis for the behavioral sciences. Hillsdale (NJ): Lawrence Erlbaum Associates; 1988.

33. Feyer A-M. Fatigue: Time to recognise and deal with an old problem. Br Med J. 2001:322:829-30. http://dx.doi. org/10.1136/bmj.322.7290.808.

34. Kompier M, Taris T. Understanding the causal relations between psychosocial factors at work and health - a circular process. Scand J Work Environ Health. 2011;37:4:259-62. http://dx.doi.org/10.5271/sjweh.3172.

35. Härmä M. Work hours in relation to work stress, recovery and health. Scand J Work Environ Health. 2006;32:502-14.

36. Lox CL, Martin Ginis, KA, Petruzzello, SJ. The psychology of exercise. Integrating theory and practice. Scottsdale (US): Holcomb Hathaway Publishers; 2010.

Received for publication: 12 July 2011 